\title{
Hypercalcemia following Alfacalcidol for Post-Surgical Hypoparathyroidism-An Underestimated Complication?
}

\author{
Catherine Leng ${ }^{1}$, Glen Charlesworth ${ }^{2}$, Emma Nofal ${ }^{1}$, Sabapathy P. Balasubramanian ${ }^{1 *}$ \\ ${ }^{1}$ Department of General Surgery, Sheffield Teaching Hospitals NHS Foundation Trust, Sheffield S10 2JF, UK \\ ${ }^{2}$ Department of Pharmacy, Sheffield Teaching Hospitals NHS Foundation Trust, Sheffield S10 2JF, UK
}

Received: August 20, 2015; Accepted: November 15, 2015; Published: December 06, 2015

*Corresponding author: Sabapathy P. Balasubramanian, Royal Hallamshire Hospital, Endocrine Surgical Unit, Sheffield Teaching Hospitals, NHS Foundation Trust, Sheffield S10 2JF, UK, Tel: +0114-226-1379; Fax: -0114-271-3710; E-mail: s.p.balasubramanian@sheffield.ac.uk

\begin{abstract}
Background: Post operative hypocalcemia is a common complication of thyroid and parathyroid surgery and is treated with calcium and/or active Vitamin D supplements, such as alfacalcidol. Although reportedly uncommon, we observed several cases of alfacalcidol induced hypercalcemia within a short period of time.

Objective: To determine the incidence alfacalcidol induced hypercalcemia in the post-surgical setting and explore factors predisposing to this complication.

Patients and Methods: This was a retrospective cohort study. All prescriptions for alfacalcidol for post-surgical hypocalcemia in a three-year period were reviewed; and clinical and biochemical characteristics of these patients were ascertained. The main outcome measure was the occurrence of hypercalcemia. Potential risk factors for hypercalcemia were also investigated.

Results: Of 61 patients prescribed alfacalcidol for post-surgical hypocalcemia, $17(27.9 \%)$ developed hypercalcemia. Of these, one patient had a significant clinical event. Exploratory analyses did not identify any potential factors that could predict the risk or severity of this complication.

Conclusions: This report serves to raise awareness of the risk of alfacalcidol induced hypercalcemia in patients with post-surgical hypoparathyroidism; which is higher than previously estimated. Given the inability to predict hypercalcemia and the variability of parathyroid recovery after surgery, serum calcium should be monitored regularly and attempts should be made to gradually withdraw active Vitamin D supplements for all patients with postsurgical hypoparathyroidism.
\end{abstract}

Keywords: Alfacalcidol; Post-surgical hypoparathyroidism; Hypocalcemia; Hypercalcemia

\section{Introduction}

Hypocalcemia is a recognized complication of thyroid surgery, with transient and long-term rates varying from 19 to $38 \%$ and 0 to $3 \%$ respectively [1]. The fourth national audit of the British Association and Endocrine and Thyroid Surgeons (BAETS) published surgeon reported rates of $26.6 \%$ and $13.6 \%$ for temporary and permanent hypocalcemia [2]. Post- surgical hypocalcemia is usually secondary to hypoparathyroidism; underlying mechanisms include direct injury or devascularization of parathyroid glands, or removal.Several riskfactors are involved, including perioperative PTH levels, preoperative vitamin D, female gender, Graves' disease, parathyroid autotransplantation or inadvertent excision [1]. It is also a potential complication of parathyroid surgery, with reported rates of around 11\% [3]. In surgery for Graves' disease and primary hyperparathyroidism, hypocalcemia may occasionally be secondary to 'hungry bone syndrome'; this refers to the rapid uptake of calcium by bones following surgery [4]. It should be noted that in this scenario, however, Parathyroid hormone (PTH) levels are relatively normal or high.

The signs and symptoms associated with hypocalcemia cover a clinical spectrum that ranges from asymptomatic to evidence of neuromuscular excitability (tingling, muscle twitches, carpopedal spasm), to more severe and potentially life- threatening complications, such as cardiac arrhythmias and seizures [5]. Treatment takes into consideration the severity of the hypocalcemia, the presence of symptoms, and the likelihood of early recovery of parathyroid function. Medical management usually involves a combination of calcium supplements and an active vitamin D. Vitamin D is a fat-soluble molecule that increases the gastrointestinal absorption of calcium, thus playing a crucial role in calcium homeostasis. Activated forms of vitamin D are preferable, as the lack of Parathyroid hormone (PTH) results in an inadequate conversion of $25-\mathrm{OH}$ vitamin $\mathrm{D}$ to the active 1, 25-dihydroxy vitamin $\mathrm{D}$, by the 1-alpha hydroxylase enzyme in the kidneys. Two forms of active vitamin D are in common use-alfacalcidol (1-OH vitamin D) and calcitriol (1, 25-dihydroxyvitamin D). The former is a pro-drug and requires 25-hydroxylation in the liver, but does not require PTH dependent 1-alpha hydroxylation. Alfacalcidol is thought to be preferable to calcitriol as the risk of hypercalcemia may be higher with calcitriol (12.2\%) than alfacalcidol (2.6\%), as demonstrated in a systematic review [6]. In addition, calcitriol has the potential to suppress parathyroid hormone to a greater extent [7]; an undesirable characteristic in post-surgical patients. 
The potential for alfacalcidol to cause hypercalcemia is well known [8-11]. The rate of hypercalcemia following alfacalcidol is however unclear; one paper suggests a rate of $2.6 \%$ [11] in a setting other than post-surgical hypoparathyroidism. The standard practice in the management of surgical hypoparathyroidism in this centre is treatment with a combination of calcium and alfacalcidol, which are then gradually withdrawn. It was noted over a period of time that seven postoperative patients on alfacalcidol developed hypercalcemia. This retrospective cohort study was therefore performed with the objective of determining the incidence of hypercalcemia in patients prescribed alfacalcidol in the post-operative setting, and exploring potential patient and treatment related factors that could be associated with the risk and/or severity of hypercalcemia.

\section{Patients and Methods}

An inductive approach was taken to address the research question in this retrospective cohort study. All alfacalcidol prescriptions were retrieved from hospital pharmacy records. Patients prescribed alfacalcidol for post-surgical hypocalcemia in a three year period (January 2010 to December 2012) by clinicians involved in the management of thyroid and parathyroid disorders were included. Patients were excluded if they did not have thyroid or parathyroid surgery or if alfacalcidol was prescribed for another condition (such as renal failure). The following data was obtained from electronic and 'hard copy' sources:

- Details of surgery, postoperative hypocalcemia and management of hypocalcemia

- Factors that may influence the risk and severity of hypercalcemia such as concomitant medications (e.g. calcium and thiazide diuretics), related biochemistry (e.g., serum vitamin D and PTH levels) and co-morbid conditions (e.g. renal failure).

- Presentation and biochemical features of hypercalcemia, if present.

The normal range for the serum biochemical measurements were $2.20-2.60 \mathrm{mmol} / \mathrm{L}$ for adjusted calcium and 15-65 ng/ L for intact parathyroid hormone. In general, calcium levels were routinely measured on the morning and afternoon of the day after surgery. Subsequent measurements were only done selectively at follow up on the basis of symptoms, need for supplements and the judgement of the treating clinician. Alfacalcidol was commenced in addition to calcium supplements in postoperative patients with significant (adjusted calcium $<2.0 \mathrm{mmol} / \mathrm{L}$ ) or symptomatic hypocalcemia. In some patients, alfacalcidol was prescribed when significant and long-term hypoparathyroidism was expected; such as following a subtotal parathyroidectomy During the period of the study, there was no formal protocol for the management of these patients and the decision to treat, dose of treatments used, duration and frequency of monitoring and decision to wean vitamin $\mathrm{D}$ and/or calcium supplements were made by treating clinician. Parathyroid hormone levels were not routinely measured. Further monitoring of biochemistry and symptoms were usually done by the surgical team and occasionally by an endocrinologist or the GP.

All data was retrieved by one observer and the second observer validate the accuracy of all biochemical values obtained from electronic records.

\section{Data Analysis}

The primary end point was the frequency of symptomatic or biochemically detected hypercalcemia (adjusted serum calcium of $\geq 2.6 \mathrm{mmol} / \mathrm{L}$ ), described as a percentage. Exploratory analyzes were undertaken to determine any associations between potential risk factors and the occurrence of hypercalcemia. The statistical tests employed to determine the significance of potential associations included Chi-square test with Yates correction or Fisher's exact test for binary variables; and the Mann Whitney U test for continuous variables (having assumed that they are not normally distributed).

This study did not require explicit consent from individual patients and was approved by the R\&D department of the Sheffield Teaching Hospitals NHS Foundation Trust (Reference number: STH18118) as an observational (retrospective cohort) study.

\section{Results}

Sixty-one patients who were prescribed alfacalcidol following thyroid and/or parathyroid surgery were included in the analysis (figure 1). There were 45 females. The median (inter-quartile range) age at surgery for these patients was 50.5 (34-66). Of these, 34 underwent thyroid surgery, 23 had parathyroid surgery and the rest $(n=4)$ had both thyroid and parathyroid surgery simultaneously. The majority of these patients were started on alfacalcidol following detection of biochemical hypocalcemia (n = 57) in the postoperative period. Two patients had symptoms of hypocalcemia after parathyroid surgery for hypercalcemia and were started on alfacalcidol despite a normal adjusted calcium level. In two patients, alfacalcidol was started prophylactically following a subtotal parathyroidectomy, despite the absence of symptoms and biochemical evidence of hypocalcemia. The median (inter-quartile range) number of days after surgery to

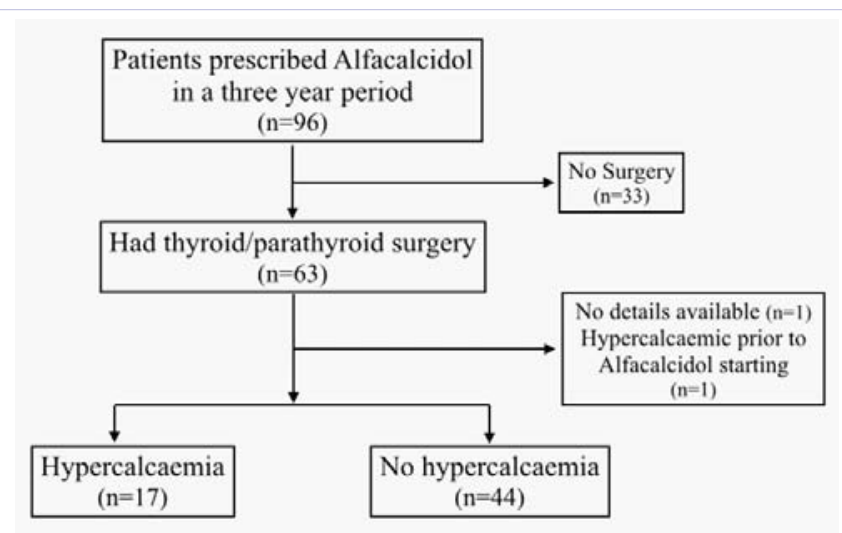

Figure 1: Flow chart demonstrating the inclusion of patients in the study. 
the initiation of treatment with alfacalcidol was 2 (1-3) days. The median (inter-quartile range) adjusted calcium level at the time of initiation of alfacalcidol treatment in patients with postoperative hypocalcemia was $1.98(1.92-2.04) \mathrm{mmol} / \mathrm{L}$.

Seventeen patients (27.9\%) developed hypercalcemia. This was detected at median (inter-quartile range) duration of 32 (4124) days. The median (inter-quartile range) adjusted calcium level when hypercalcemia was first detected in this cohort was 2.71 (2.63-2.82) $\mathrm{mmol} / \mathrm{L}$. The median (inter-quartile range) of the highest adjusted calcium level in this group was 2.71 (2.64- 2.84) mmol/L. Further characteristics of these patients are demonstrated in Table 1. Apart from concomitant calcium supplements, no patient was found to be on other medications (such as thiazide diuretics) that could exacerbate hypercalcemia. Following the occurrence of hypercalcemia, supplements were either stopped or reduced in all patients. Patients were monitored closely and appropriate dose adjustments to alfacalcidol were made as considered necessary by the treating clinician.

Comparison of patients who did and did not develop hypercalcemia did not reveal any significant differences in age, gender, initial dose of alfacalcidol, calcium supplements, type of surgery, adjusted serum calcium or PTH levels prior to starting alfacalcidol (Table 2).

\section{Discussion}

The occurrence of hypercalcemia in patients on alfacalcidol for postoperative hypocalcaemia is thought to be rare, but several patients in this institution were noted to have this complication by the senior author; worryingly two patients had acute renal impairment secondary to hypercalcemia. A literature review demonstrated several case reports describing hypercalcemia in patients receiving calcium and vitamin D supplements for postoperative hypoparathyroidism. The vitamin D supplements included alfacalcidol [8,12], calcitriol [13-15] and dihydrotachysterol [16]. Given the paucity of data and the lack of cohort studies in this population, this systematic study was undertaken.

The results of this retrospective cohort study demonstrate that a significant proportion of patients $(27.9 \%)$ developed hypercalcemia following the prescription of alfacalcidol for postoperative hypoparathyroidism. This is much higher than that previously reported in other settings [11]. A likely explanation for this phenomenon is the closer biochemical monitoring of these patients, use of relatively high doses of alfacalcidol (0.25-2.00 $\mathrm{mcg} /$ day) in the postoperative setting, and the variability in the speed and extent of recovery of parathyroid function following surgery. The authors' current practice and outcomes with regards to post thyroidectomy hypocalcemia rates (temporary and long term hypocalcemia of 35\% and 5.5\% respectively) have been reported recently [17]. Patients are usually only started on alfacalcidol and calcium supplements if the hypocalcemia is significant $(<2.0 \mathrm{mmol} / \mathrm{L})$ and/or symptomatic. While it is possible that premature prescription of alfacalcidol may have contributed to hypercalcemia, this complication did not occur in any of the four patients in whom alfacalcidol was started for hypocalcemic symptoms or in a prophylactic manner. Moreover, there was no association between the dose of either alfacalcidol or calcium supplements and the occurrence of hypercalcemia.

No treatment or patient related variable (including pre alfacalcidol calcium or PTH levels) was associated with hypercalcemia. The lack of influence of the dose of alfacalcidol and calcium salts on the risk of hypercalcemia probably reflects the unpredictable nature of parathyroid gland recovery. Delayed recovery of parathyroid glands has been shown to occur many years following surgery [18].

Active vitamin D supplements such as alfacalcidol are invaluable in the management of post-thyroidectomy hypocalcemia. This series demonstrates the risk of hypercalcemia; awareness of which should result in early identification and prompt treatment of the complication. For patients with post-surgical hypocalcemia, we recommend monitoring of both calcium and PTH levels every few weeks and tailoring of the dose of alfacalcidol and calcium supplements to maintain adjusted calcium levels between 2.0 and $2.2 \mathrm{mmol} / \mathrm{L}$ [19]. Any coexisting vitamin D deficiency should be treated with inactive vitamin D treatment (such as cholecalciferol). Gradual withdrawal of supplements should be attempted in patients with an adjusted calcium level of $>2.2 \mathrm{mmol} / \mathrm{L}$. Alfacalcidol should be withdrawn (in steps of $0.25 \mathrm{mcg} /$ day at a time), especially in patients with PTH levels in the normal range. The result of this report has been disseminated to clinicians in the departments of endocrine surgery, endocrinology and oncology. Current practice has changed to include routine measurement of PTH levels after surgery and institution of a formal protocol to monitor adjusted calcium and PTH levels every few weeks in patients on supplements, treat co-existing vitamin D deficiency and facilitate gradual withdrawal of alfacalcidol and calcium supplements in asymptomatic patients with normal adjusted calcium levels. In patients where alfacalcidol is required long term, the interval between calcium checks is gradually extended to 6-12 months.

This retrospective study is restricted by inherent limitations in a study of this design. The sample size is small, but adequate to convey an important clinical message. As patients were initially identified from the hospital pharmacy database, both new and repeat alfacalcidol prescriptions were included in this study. The study therefore includes patients who have been on alfacalcidol for long periods of time. However, the methodology is appropriate as this was intended to be a pragmatic study, with the aim of determining the incidence of hypercalcemia in a patient population at risk (i.e. those on alfacalcidol in a given time period). Despite the significant proportion of patients who developed hypercalcemia, only one had a significant clinical event. This could be attributed to clinician awareness of this potential side effect following the detection of the first few cases. This may have resulted in adjustment of clinical practice (with more frequent and close monitoring of adjusted calcium levels) within the department. Five patients developed hypercalcemia within a week of initiation of alfacalcidol supplements. It could be argued in hindsight that these patients may not have needed active vitamin D treatment. However, this could not be predicted 


\begin{tabular}{|c|c|c|c|c|c|c|c|c|}
\hline \multicolumn{2}{|c|}{ Patient characteristics } & \multicolumn{2}{|c|}{$\begin{array}{l}\text { Biochemistry } \\
\text { at initiation of } \\
\text { alfacalcidol }\end{array}$} & \multirow{2}{*}{$\begin{array}{l}\text { Alfacalcidol } \\
\text { initial dose } \\
\text { (mcg/da) }\end{array}$} & \multirow{2}{*}{$\begin{array}{l}\text { Time to } \\
\text { hypercalcemia } \\
\text { from start of } \\
\text { alfacalcidol }\end{array}$} & \multicolumn{2}{|c|}{$\begin{array}{l}\text { Findings when } \\
\text { hypercalcemic }\end{array}$} & \multirow{2}{*}{$\begin{array}{l}\text { Presentation of } \\
\text { hypercalcemia }\end{array}$} \\
\hline Age/Sex & Surgery & $\begin{array}{l}\text { Adjusted } \\
\text { serum } \\
\text { calcium } \\
(\mathrm{mmol} / \mathrm{L})\end{array}$ & $\begin{array}{l}\text { Serum } \\
\text { PTH } \\
\text { (ng/L) }\end{array}$ & & & $\begin{array}{l}\text { Adjusted } \\
\text { serum } \\
\text { calcium } \\
(\mathrm{mmol} / \mathrm{L})\end{array}$ & $\begin{array}{l}\text { Serum } \\
\text { PTH } \\
\text { (ng/L) }\end{array}$ & \\
\hline $49 \mathrm{~F}$ & $\begin{array}{l}\text { Thyroid (hemi- } \\
\text { thyroidectomy) and } \\
\text { parathyroid surgery } \\
\text { (single gland excision) }\end{array}$ & 2.00 & 9.1 & 1 & 28 days & 2.60 & 2.5 & Biochemical \\
\hline $16 \mathrm{~F}$ & $\begin{array}{l}\text { Total thyroidectomy in } \\
\text { MEN2 patient }\end{array}$ & NA & NA & 2 & Unknown & 2.69 & NA & NA \\
\hline $34 \mathrm{M}$ & $\begin{array}{l}\text { Parathyroid surgery } \\
\text { (single gland excision) }\end{array}$ & 2.03 & 263 & 1 & 110 days & 2.63 & 20.1 & Biochemical \\
\hline $69 \mathrm{~F}$ & $\begin{array}{l}\text { Parathyroid surgery } \\
\text { (single gland excision) }\end{array}$ & 1.98 & 242.9 & 0.25 & 22 days & 3.10 & 506 & Biochemical \\
\hline $82 \mathrm{~F}$ & $\begin{array}{l}\text { Total thyroidectomy } \\
\text { and central node } \\
\text { dissection for PTC }\end{array}$ & 1.63 & 10.8 & 1 & 65 days & 2.71 & 10 & Biochemical \\
\hline $64 \mathrm{~F}$ & $\begin{array}{l}\text { Total thyroidectomy } \\
\text { and central neck } \\
\text { dissection for PTC }\end{array}$ & 1.97 & $<5$ & 1 & 179 days & 2.80 & 3 & Biochemical \\
\hline $53 \mathrm{M}$ & $\begin{array}{l}\text { Subtotal } \\
\text { parathyroidectomy } \\
\text { and thymectomy for } \\
\text { tertiary HPT }\end{array}$ & 1.93 & 5 & 0.5 & 33 days & 3.74 & 4 & $\begin{array}{l}\text { Acute admission } \\
\text { with dehydration } \\
\text { and renal } \\
\text { impairment }\end{array}$ \\
\hline $62 \mathrm{~F}$ & $\begin{array}{l}\text { Total thyroidectomy } \\
\text { and central neck } \\
\text { dissection for PTC }\end{array}$ & 2.00 & 12 & Unknown & Unknown & 2.75 & NA & NA \\
\hline $57 \mathrm{~F}$ & $\begin{array}{l}\text { Total thyroidectomy } \\
\text { for toxic goiter }\end{array}$ & 1.81 & 49 & 1 & 70 days & 2.69 & 85 & Biochemical \\
\hline $80 \mathrm{~F}$ & $\begin{array}{l}\text { Total thyroidectomy } \\
\text { and central node } \\
\text { dissection for PTC }\end{array}$ & 1.51 & 14 & 1 & 2 days & 2.88 & 13 & Biochemical \\
\hline $57 \mathrm{~F}$ & $\begin{array}{l}\text { Subtotal } \\
\text { parathyroidectomy for } \\
\text { PHPT }\end{array}$ & 2.05 & 19 & 1 & 2 days & 2.75 & 19 & Biochemical \\
\hline $22 \mathrm{~F}$ & $\begin{array}{l}\text { Total thyroidectomy } \\
\text { for Graves' disease }\end{array}$ & 1.94 & 27 & 0.5 & 5 days & 2.70 & 27 & Biochemical \\
\hline $25 \mathrm{M}$ & $\begin{array}{l}\text { Subtotal } \\
\text { parathyroidectomy and } \\
\text { thymectomy for PHPT } \\
\text { (MEN1 syndrome) }\end{array}$ & 1.98 & 10 & 1 & 3 days & 2.65 & 5 & Biochemical \\
\hline $42 \mathrm{M}$ & $\begin{array}{l}\text { Total thyroidectomy } \\
\text { with central and } \\
\text { left selective neck } \\
\text { dissection for PTC }\end{array}$ & 2.10 & 9 & 0.5 & 15 days & 2.64 & 18 & Biochemical \\
\hline $43 \mathrm{~F}$ & $\begin{array}{l}\text { Total thyroidectomy } \\
\text { and right central neck } \\
\text { dissection for PTC }\end{array}$ & 2.01 & 5 & 1 & 1 day & 2.61 & 11 & Biochemical \\
\hline $73 \mathrm{~F}$ & $\begin{array}{l}\text { Total thyroidectomy, } \\
\text { central and right } \\
\text { selective neck } \\
\text { dissection for PTC }\end{array}$ & 1.77 & $<2.5$ & 1 & 679 days & 2.74 & 49 & Biochemical \\
\hline $52 \mathrm{M}$ & $\begin{array}{l}\text { Subtotal } \\
\text { parathyroidectomy for } \\
\text { PHPT }\end{array}$ & 1.87 & NA & NA & NA & 2.69 & NA & NA \\
\hline
\end{tabular}

Abbreviations: PHPT: Primary Hyperparathyroidism; PTC: Papillary Thyroid Cancer; MEN: Multiple Endocrine Neoplasia; NA: Not Available 
Table 2: Comparison of potential risk factors in patients with and without hypercalcemia.

\begin{tabular}{|c|c|c|c|}
\hline Factor & $\begin{array}{l}\text { Patients developing } \\
\text { hypercalcemia }\end{array}$ & $\begin{array}{l}\text { Patients not developing } \\
\text { hypercalcemia }\end{array}$ & p-value \\
\hline Median (inter-quartile range) age & $49(34-66)$ & $49(34-66)$ & $p=0.628^{\#}$ \\
\hline Gender (M/F) & $5 / 12$ & $11 / 33$ & $p=0.979^{\wedge}$ \\
\hline $\begin{array}{l}\text { Median (IQR) alfacalcidol dose in } \\
\text { mcg at initiation }\end{array}$ & $\begin{array}{l}1(0.5-1.0) \\
(\mathrm{n}=15)^{* *}\end{array}$ & $\begin{array}{l}1(0.5-1.0) \\
(\mathrm{n}=37)^{* *}\end{array}$ & $p=0.319^{\#}$ \\
\hline $\begin{array}{l}\text { Median (IQR)dose of calcium in } \\
\text { grams at initiation of alfacalcidol }\end{array}$ & $\begin{array}{l}2.5(1.6-3.75) \\
(\mathrm{n}=8)^{* *}\end{array}$ & $\begin{array}{l}2.4(2-3) \\
(\mathrm{n}=25)^{* *}\end{array}$ & $p=0.821^{\#}$ \\
\hline $\begin{array}{l}\text { Surgery (thyroid / parathyroid / } \\
\text { both) }\end{array}$ & $10 / 6 / 1$ & $24 / 17 / 3$ & $p=1.0^{+}$ \\
\hline $\begin{array}{l}\text { Median (inter-quartile range) pre- } \\
\text { alfacalcidol adjusted serum calcium } \\
\text { level }\end{array}$ & $\begin{array}{l}1.98(1.95-2.09) \\
(\mathrm{n}=16)^{* *}\end{array}$ & $\begin{array}{l}1.98(1.94-2.09) \\
(\mathrm{n}=43)^{* *}\end{array}$ & $p=0.103^{\#}$ \\
\hline $\begin{array}{l}\text { Median (inter-quartile range) pre- } \\
\text { alfacalcidol PTH level }\end{array}$ & $\begin{array}{l}11.4(8-32.5) \\
(\mathrm{n}=14)^{* *}\end{array}$ & $\begin{array}{l}11.65(7.33-25.5) \\
(\mathrm{n}=36)^{* *}\end{array}$ & $p=0.85^{\#}$ \\
\hline
\end{tabular}

\# Mann Whitney U test; ^ Chi-square with Yates correction; + Fisher’s exact test. ${ }^{* *}$ Number where data was available

on the basis of calcium or PTH levels at the time of initiation of alfacalcidol (Tables 1 and 2).

In summary, this study has highlighted that the risk of alfacalcidol induced hypercalcemia in the post-operative 'hypoparathyroid' patient is considerably higher than what literature would suggest. Given the consequences of prolonged hypercalcemia and the difficulty in predicting parathyroid recovery in this subset of patients, regular monitoring of adjusted calcium levels and a concerted attempt to gradually withdraw alfacalcidol supplements is strongly recommended.

\section{References}

1. Edafe O, Antakia R, Laskar N, Uttley L, Balasubramanian SP. Systematic review and meta-analysis of predictors of post-thyroidectomy hypocalcaemia. Br J Surg. 2014;101(4):307-20. doi: 10.1002/bjs.9384

2. Chadwick DR, Kinsman R. The British Association of Endocrine and Thyroid Surgeons. Fourth National Audit Report. 2012;1-184.

3. Bergenfelz A, Jansson S, Mårtensson H, Reihnér E, Wallin G, Kristoffersson A, et al. Scandinavian Quality Register for Thyroid and Parathyroid Surgery: audit of surgery for primary hyperparathyroidism. Langenbecks Arch Surg. 2007;392(4):445-51.

4. Dembinski TC, Yatscoff RW, Blandford DE. Thyrotoxicosis and hungry bone syndrome--a cause of posttreatment hypocalcemia. Clin Biochem. 1994:27(1);69-74.

5. Fong J, Khan A. Hypocalcemia: updates in diagnosis and management for primary care. Can Fam Physician. 2012;58(2):158-62.

6. Bjelakovic G, Gluud LL, Nikolova D, Whitfield K, Wetterslev J, Simonetti RG, et al. Vitamin D supplementation for prevention of mortality in adults. Cochrane Database Syst Rev. 2011;(7):CD007470. doi: $10.1002 / 14651858$.

7. Moe S, Wazny LD, Martin JE. Oral calcitriol versus oral alfacalcidol for the treatment of secondary hyperparathyroidism in patients receiving hemodialysis: a randomized, crossover trial. Can J Clin Pharmacol. 2008;15(1):e36-43.

8. Paterson CR. Hypercalcaemia in alphacalcidol therapy. Postgrad Med J. 1981;57(669):431-2.
9. Hamdy RC, Coles JA, Downey LJ. A comparative study of cholecalciferol, dihydrotachysterol and alfacalcidol in the treatment of elderly patients with hypocalcaemia. Age Ageing. 1987;16(3):178-80.

10. Menczel J, Foldes J, Steinberg R, Leichter I, Shalita B, Bdolah-Abram T, et al. Alfacalcidol (alpha D3) and calcium in osteoporosis. Clin Orthop Relat Res. 1994;(300):241-7.

11. Dukas L, Bischoff HA, Lindpaintner LS, Schacht E, Birkner-Binder D, Damm TN, et al. Alfacalcidol reduces the number of fallers in a community-dwelling elderly population with a minimum calcium intake of more than 500 mg daily. J Am Geriatr Soc. 2004;52(2):230-6.

12. Fujiwara T. Vitamin D-related progressive renal insufficiency in an elderly patient with postsurgical hypoparathyroidism associated with extensive brain calcification. Nihon Jinzo Gakkai Shi. 2012;54(1):40-7.

13.Tal A, Powers K. Milk-alkali syndrome induced by 1,25(OH)2D in a patient with hypoparathyroidism. J Natl Med Assoc. 1996;88(5):313-

14. Nabhan FA, Sizemore GW, Camacho PM. Milk-alkali syndrome from ingestion of calcium carbonate in a patient with hypoparathyroidism. Endocr Pract. 2004;10(4):372-5

15. Fernandez-Garcia M, Vazquez L, Hernandez JL. Calciumalkali syndrome in post-surgical hypoparathyroidism. QJM. 2012;105(12):1209-12. doi: 10.1093/qjmed/hcr179.

16. Boots JM, Burghouts JT, Jansen JL. Unaccountable severe hypercalcemia in a patient treated for hypoparathyroidism with dihydrotachysterol. Neth J Med. 1999;54(1):16-20.

17. Edafe O, Prasad P, Harrison BJ, Balasubramanian SP. Incidence and predictors of post-thyroidectomy hypocalcaemia in a tertiary endocrine surgical unit. Ann R Coll Surg Engl. 2014;96(3):219-23. doi: $10.1308 / 003588414 X 13814021679753$

18. Cusano NE, Anderson L, Rubin MR, Silva BC, Costa AG, Irani D. Recovery of parathyroid hormone secretion and function in postoperative hypoparathyroidism: a case series. J Clin Endocrinol Metab. 2013;98(11):4285-90. doi: 10.1210/jc.2013-2937.

19. Khan MI, Waguespack SG, Hu MI. Medical management of postsurgical hypoparathyroidism. Endocr Pract. 2011;17 Suppl 1:18-25. doi: 10.4158/EP10302. 